\title{
Innovative and sustainable toothpaste packaging design
}

\begin{abstract}
Oral care products and especially toothpastes, are vital for the human daily hygiene. Nowadays tooth brushing is, without a doubt, an integral part of preventative dentistry, but on the other hand the extensive use of toothpastes has a great impact on the environment. Traditional toothpaste tubes have many negative aspects, in terms of usage and recycling. Their modest size, mixed and merged materials, remnant toothpaste inside toothpaste tubes and other tube based containers, make them difficult to disassemble and recycling almost impossible. The main objective of this study, is to investigate the disadvantages of the toothpaste packaging and the proposal of new innovative packaging solutions, which will not only reduce the environmental impact that traditional toothpaste tubes cause, but will also be user-friendly. In this paper, a combination of literature survey and market research is being presented. Finally, based on the findings and well-established techniques, a number of innovative, user and environmental friendly toothpaste packaging is proposed.
\end{abstract}

\section{KEY WORDS}

Packaging design, toothpaste, eco-design, sustainability

\author{
Anastasia Malea ${ }^{1}$ (1) \\ Anastasios Tzotzis ${ }^{2}$ (B) \\ Athanasios Manavis ${ }^{2}$ (B) \\ Panagiotis Kyratsis ${ }^{2}$ \\ ${ }^{1}$ International Hellenic University, \\ School of Science and Technology, \\ Thermi, Greece \\ ${ }^{2}$ University of Western Macedonia, \\ Department of Product and \\ Systems Design Engineering, Kila \\ Kozani, Greece
}
Corresponding author: Panagiotis Kyratsis e-mail: pkyratsis@uowm.gr

\section{Introduction}

Nowadays, more and more consumer product industries lean towards sustainability and green manufacturing. Thus, areas such as eco-friendly packaging design attract many researchers. Svanes et al. (2010) described a holistic methodology for sustainable packaging design. With the proposed methodology authors studied the combined systems of packaging and the packaged products across the whole distribution chain, from manufacturer to end consumer and the life cycle from raw material extraction to the waste phase. Alexopoulos, Kyratsis \& Efkolidis (2011) used the principles of industrial design engineering and the use of advanced CAD/CAM systems to propose a number of different innovative packaging designs for traditional products. These designs can be used for both the everyday consumption as well as the feta cheese touristic promotion. Ulrich \& Eppinger (2012) analyzed techniques of concept generation and selection in order to reach the stage of testing and manufacturing. Efkolidis \& Kyratsis (2012) focused on the development of a novel methodology called Ecology Push that aims to help designers to educate customers through their work and motivate them towards a more sustainable way of life. This methodology takes into consideration the economic and environmental aspects of product design. Kyratsis et al. (2015) used a different approach in nature-based methodology which uses similarities based on the geometrical form or/and the functionality. The proposed conceptual product design framework supports and highlights the necessity of a nature-based design to all product industries. Dimou et al. (2017) 
presented a case study that refers to the design of an intelligent, programmable shoe for pregnant women made of synthetic biological material. Authors implemented a research methodology based on a literature review and a series of interviews with some of the experts in the field of physiotherapy. Manavis et al. (2019) proposed a nature-based conceptual product design methodology and included in their work a number of case studies of in-store displays. The work by Carli Lorenzini \& Olsson (2019) aimed to increase knowledge about medication and health care products packaging. In addition, authors presented the constraints that occur during the design process of such packaging concepts. Kovačević, Brozović \& Itrić Ivanda (2019) investigated the influence of the eco-mark on the product packaging to the perception of the product and the attractiveness of its packaging by carrying out two different experiments.

The main objective of this study, is to investigate the disadvantages of the toothpaste packaging and the proposal of a new packaging solution, which will not only eliminate the environmental impact that traditional toothpaste tubes cause, but is also user-friendly. After a brief marketing research of toothpaste market and the presentation of the new packaging designs, an environmental analysis was performed with the SolidWorks ${ }^{\mathrm{TM}}$ Sustainability module, in order to select the most sustainable materials and the most sustainable manufacturing method suitable for the specific design.

\section{Research and Analysis of the Design}

\section{Market research}

The growing awareness of oral hygiene, product innovation in new market segments and the frequency of launching in existing segments, have led to a large increase of sales in major markets worldwide. As a result, the toothpaste market is regarded as one of the most dynamic parts in the oral hygiene market.

According to data from Global Industry Analysts, in 2012, Europe is considered to be the largest toothpaste market in the world and its value is estimated to be US\$5 billion, with UK having precedence, while Asia Pacific is considered to be the fastest growing market of toothpaste globally, with annual growth rate of over $4 \%$ (Sriram \& Pugalanthi, 2013). In particular for the United Kingdom, the share of the toothpaste market is $£ 330$ million from the total amount of $£ 840$ million. As a result, there is a large increase in competition in order to differentiate the toothpaste on the shelves of supermarkets, and manufacturers, have made efforts to turn the toothpaste into high quality product, according to specific dental needs and age groups. Thus packaging options for consumers are countless and clearly upgraded. They range from pump dispensers to aerosols, and brands in order to attract the attention of consumers, they have turned into bright metallic prints with outer cartons to be decorated with foil blocking, high color printing and other more special techniques such as embossing and holographic printing that provide more intricate textures.

In general, there is the perception that the use of metallic and foiling in a packaging supports the value of the brand and gives a more luxurious feel to the product. On the other hand, a visit to the supermarket, proves that the industry is still dominated by the tube, a packing device which first appeared in 1892, and despite the efforts for innovation in packaging, consumers do not dare to change their habits, while the competition game is held between the main OEMs that have the five leading brands in sales.

Another demonstration of how slowly this sector evolves, is the adoption of laminate tubes globally. Although today, metal tubes have been eliminated and replaced by polyethylene (PE) or aluminum laminates, it took several decades from their initial launch in 1972 to be established. Australia had the exclusive sale of plastic in 1983 and began to penetrate into the Chinese market in 1997, when an Indian manufacturer of Essel Propack, started operating there (Elliot, 2010).

Today the introduction of laminate packaging has increased significantly in many types of packaging apart from the toothpaste, such as coffee packs and pet food pouches, as the benefits that offers, compared to the established packages, are numerous. Nevertheless, the presence of residual product in combination with the difficult separation of the laminate, makes the recycling process particularly difficult or impossible. An assessment of the size of the UK market, which is estimated at 193000 tons of packaging annually, containing an average of $97 \%$ aluminum foil by weight and the growth rate of laminated packaging in about $10 \%$ per year, are sufficient to consider the damage being done to the environment (Slater \& Chrichton, 2011).

Below is a list of all types of toothpaste packaging that are commercially available until now:

- Metal tubes

- Plastic tubes

- Laminate tubes

- Stand-up tubes

- Pumps

\section{Environmental approach for design}

As simple toothpaste tubes become more complex, the more they harm the environment. Old style aluminum tubes, made from a single slug of metal, were much 
more recyclable than laminated ones, who replaced them. On the other hand, the extraction of bauxite, from which aluminum is made, is also detrimental to the environment, as the melting process is much more energy intensive. In addition, tubes that are still made of aluminum, may carry a label stating that they are recyclable, but in fact a disposable tube of toothpaste, which has product residues, a plastic cap and a thread, is not welcomed in an aluminum can. Switching from the use of aluminum to the use of plastic for the tubes, it could be a positive action in environmental terms, but dentifrice residues can give rise to the same problem. A plastic tube, may contain high contamination to be introduced into a recycling system, while it takes about 4000 empty plastic tubes to convert into a ton of plastic (Stypka et al., 2005). The benefits of laminates, from performance aspect are numerous and therefore its use is growing rapidly. In contrast to these advantages, laminated packaging systems have a serious drawback. The combination of plastic and aluminum in the waste, presents a technical challenge to recycle them, so these materials are discarded by conventional means (Slater \& Chrichton, 2011). Environmentally this is undesirable, since aluminum and plastic resources used for production, are wasted and should be extracted from the nature, in order to renew them. This has consequences on economic level too, as this method is very costly and the significant value of both the aluminum and the plastic could be exploited, if there was a sustainable way to recycle (Slater \& Chrichton, 2011). Despite their lightweight nature and the relatively low price, so far they are strictly non-recyclable, since the collection and recovery of recyclates is driven by weight-based targets. It could be applied, if replaced by heavier packaging options, but again their viability is controversial. There is currently no sufficient and proven technology, capable of separating the plastic from aluminum, and to fully recycle these materials in an efficient and cost effective manner (Slater \& Chrichton, 2011). The only sophisticated plastic / aluminum laminate recycling operation created by Enval Company, which was formed after research at Cambridge University's Chemical Engineering Department, where they managed to separate the aluminum from laminate by heating it in low oxygen environment to evaporate the plastic. After 12 months of operation of a pilot project conducted at Cambridge, the company has now opened a large-scale plant in Luton. Although Enval collaborates with major toothpaste brand owners to develop a recycling certification system, this expertise is not yet widespread around the world (Elliot, 2010).

Another issue that burdens the environment, and should be reviewed if its use is necessary, is the cardboard outer box. Cartons and tubes cooperate as a system for the protection of the product during distribution and provide stability to the retail shelf, while their use ends there. Typically they weigh $14.5 \mathrm{gr}$ for a tube of $100 \mathrm{ml}$. Whilst through the years, it has been observed that the energy and the material used for the tube, has been reduced significantly with the aid of the carton box, as wastage would be greater if destroyed (INCPEN, 2011). This of course, could change if there were attempts to redesign the packaging of the toothpaste. In dental care products containing medicinal application, an instruction leaflet may be necessary, so it still remains essential a packing box. Nevertheless, the tendency for packages such as plastic stand-up tubes, which do not require an external box, is constantly concerning toothpaste brands. Another view prevails, which claims that consumers should extend the end-use of products manufactured after the collection and processing of recycled materials. Of course, a toothpaste carton may consist at $80 \%$ of recycled paper, but this does not imply that it is good to use packages that are no longer necessary. For that reason, it is important to take seriously into account contagion effects that lead to certain changes made in the name of improving the environment (Stypka et al., 2005). Finally, toothpaste residues caused by each type of tube, where the toothpaste is packed, definitely worth mentioning, since they not only hinder the recycling process, but also have an overall negative impact on both users and the environment.

\section{Packaging design requirements}

The simultaneous satisfaction of all the design guidelines is a major challenge in the design process as there may be conflicting features which are not feasible to be compatible. In Table 1, these requirements have been recorded, and divided into four basic categories, based on functionality, ergonomics, sustainability and aesthetics, so that it becomes easier to understand user needs, and they are presented in a hierarchical order so that later can become an essential criterion in the concept selection stage.

\section{Table 1}

Design requirements

\begin{tabular}{|c|c|}
\hline Functionality & Ergonomics \\
\hline $\begin{array}{l}\text { Maintain the product fresh } \\
\text { Ability to stand up } \\
\text { Possibility of Controlled Dosage } \\
\text { Reduce UPR levels (facilitate empting) } \\
\text { Re-closability } \\
\text { Avoid accidental losing the lid } \\
\text { Safety lock } \\
\text { Range of sizes based on needs } \\
\text { Travel size - Portability } \\
\text { Modularity - space saving (enhance } \\
\text { stacking, warehousing, shelf } \\
\text { display and transportation) }\end{array}$ & $\begin{array}{l}\text { Minimizing required force } \\
\text { Ergonomic grip - stable holding } \\
\text { Ability to use with one hand } \\
\text { Ease of opening - closing } \\
\text { Facilitate left - right hand use } \\
\text { Prevent slipperiness } \\
\text { Intuitive use } \\
\text { Narrative Instructions } \\
\text { Indicate residual quantity } \\
\text { Differentiation of product range }\end{array}$ \\
\hline Sustainability & Aesthetics \\
\hline $\begin{array}{l}\text { Avoid over-packaging } \\
\text { Use of sustainable materials } \\
\text { Recyclability } \\
\text { Reusability } \\
\text { Reduced waste bulk } \\
\text { Possibility of cleaning residues of } \\
\text { container } \\
\text { Facilitate disassembly for material } \\
\text { separation }\end{array}$ & $\begin{array}{l}\text { Harmonization with bathroom } \\
\text { environment } \\
\text { Differentiation from competitive } \\
\text { products } \\
\text { Follow packaging trends } \\
\text { Make fashion statement } \\
\text { Natural - Eco Aesthetic } \\
\text { Provide a sense of purity } \\
\text { and freshness }\end{array}$ \\
\hline
\end{tabular}




\section{Ideation}

For the creation of the initial concepts, some tools were used, in order to enhance the creative process and trigger the generation of new ideas. In this phase, the brainstorming technique was employed which is a proven tool for such cases (Vasileiadis et al., 2019), while an attempt for mapping these ideas, as shown in Figure 1, with central axis the design requirements mentioned above. At this point, it is important to mention that the decomposition of the main problem and the treatment of each sub problem separately, were particularly helpful to propose solutions, which lead to the creation of initial ideas.

Subsequently, a visual representation of the proposed solutions presented in the mind map above, was carried out with the ultimate aim to be further interpreted and to study the possibility of their achievement. Inspiration was drawn from either various existing mechanisms, either by nature and created a fertile ground for the study of more specific characteristics that can contribute to the creation of an integrated concept as structure, form, color, texture, materials, as well as aesthetic qualities.

\section{Concept Generation}

\section{Conceptual structures}

The next step of this study was the investigation of the morphological features of the object under design. Based on the design requirements that are included in Table 1 , it is concluded that the criteria that primarily affect the structural elements of the packaging are mainly ergonomic. Some of them are steadiness of holding, left- right hand usage, minimization of slipperiness and intuitive use. From the perspective of sustainability, the recyclability also played an important role. As a key condition a number of issues were identified i.e. the cleaning capability of residues, disassembling for separating materials and the possibility of reusing the outer case by replacing the spare part. Finally, a key factor that affects the aesthetics, when designing a package, is the brand identity, which is not taken to consideration in the current design brief (the redesign of a commercial brand). Together with the conceptual structure investigated the prospect of creating a virtual brand that could incorporate aesthetical criteria was considered.

Figure 2 illustrates the exploration of different structural concepts and the inspiration drawn either by nature or from objects of art or the aesthetics communicated from perfume bottles. At the same time, upgrading of toothpaste aesthetics could be accomplished by achieving harmonization with the bathroom environment.

\section{Presentation of the selected concept}

The main objective and concern, on which the idea of the proposed design concept was based is to improve the operating mechanism of the toothpaste. In order to accomplish this, several tests were conducted and many combinations of the proposed solutions were created, some of which were rejected by the

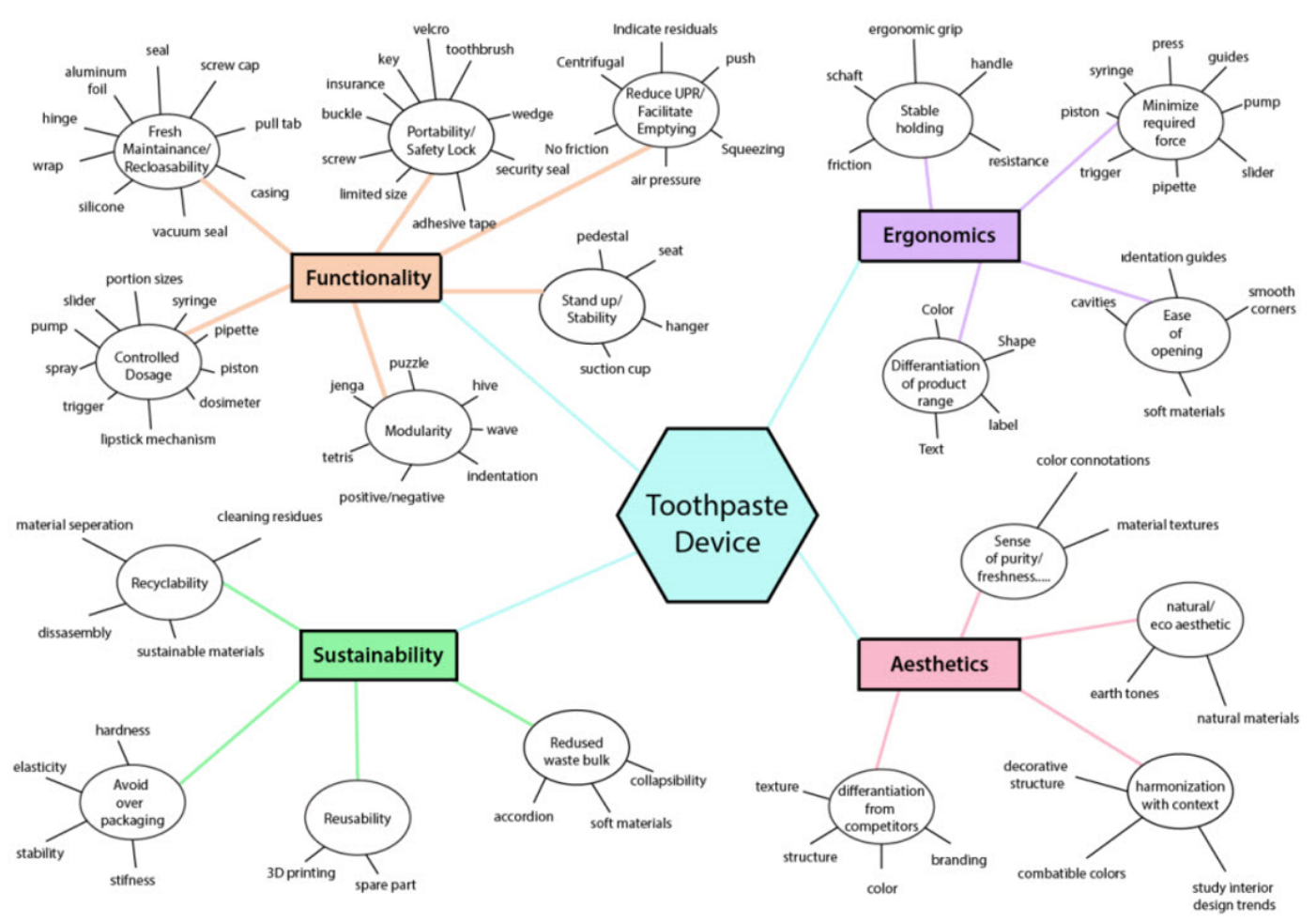

» Figure 1: Mind map based on the design requirements 


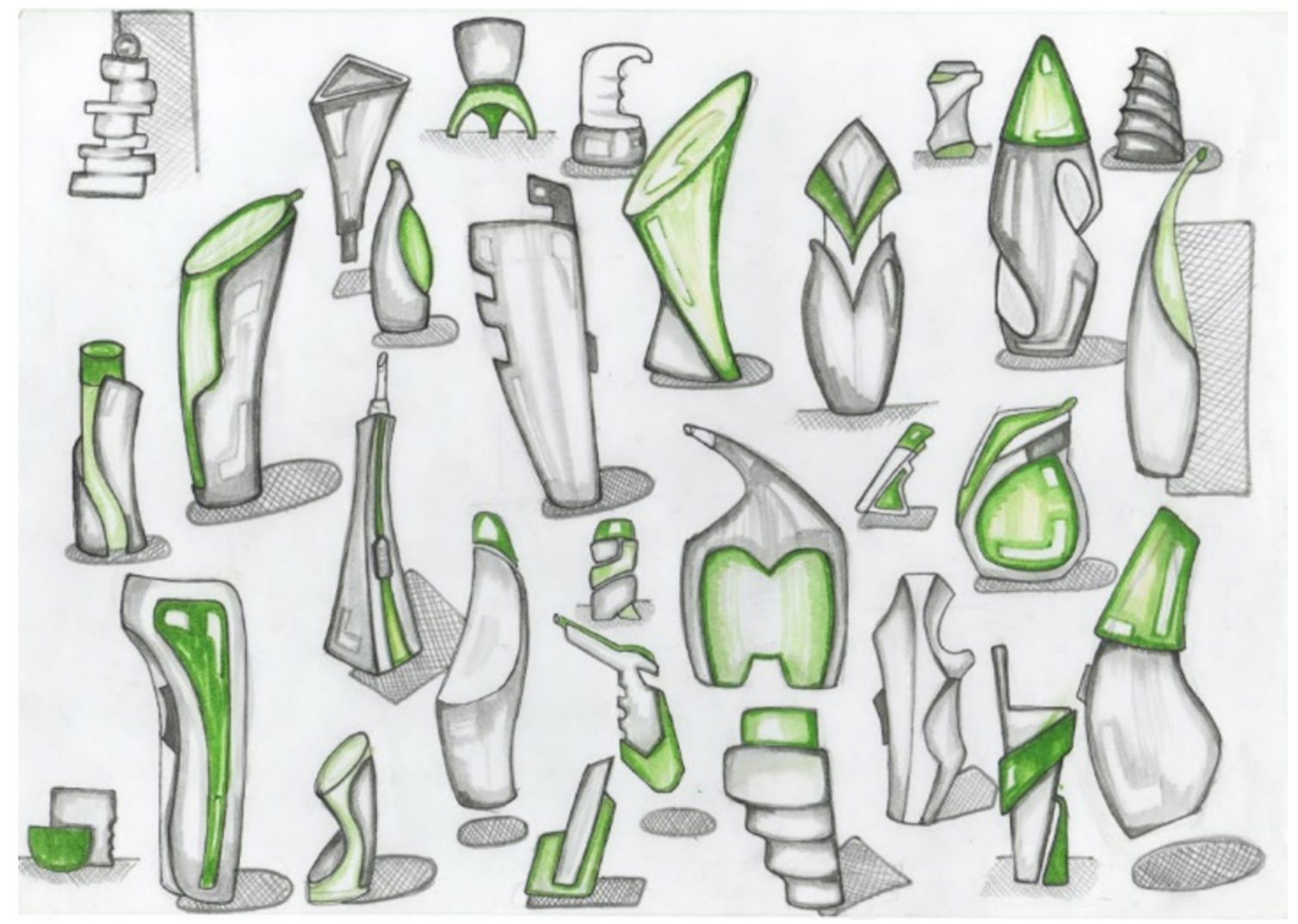

» Figure 2: Conceptual structures sketches

hierarchy of the design requirements or because some solutions of these contradicted some other design guidelines, such as the ability to use with one hand, which is particularly important for the smooth operation of the tooth brushing process. Hence the selected concept, which meets the majority of design requirements, is based on the piston mechanism.

Some of the advantages offered by this mechanism are the following:

- the required strength of the piston stays constant throughout the following path

- the flow velocity can be maintained constant

- the path length is easily and accurately adjusted

- the sliding speed of the mov-

able head is relatively low

- smooth and linear movement

- silent operation

Figure 3 illustrates the operation of the basic idea of the main mechanism on which the development of the final concepts is based. This mechanism consists of the main vessel, which is open at the bottom and is filled with toothpaste. The providing of the dentifrice is extracted from the vessel with the aid of a piston, following the movement on the shifting axis, from position 0 to position 1 , as shown in Figure 3. The piston has bonded to its surface, a rubber component, which assists by friction with the walls of the container, the extrusion of the dentifrice abroad and simultaneously provides the airtight seal of the container.

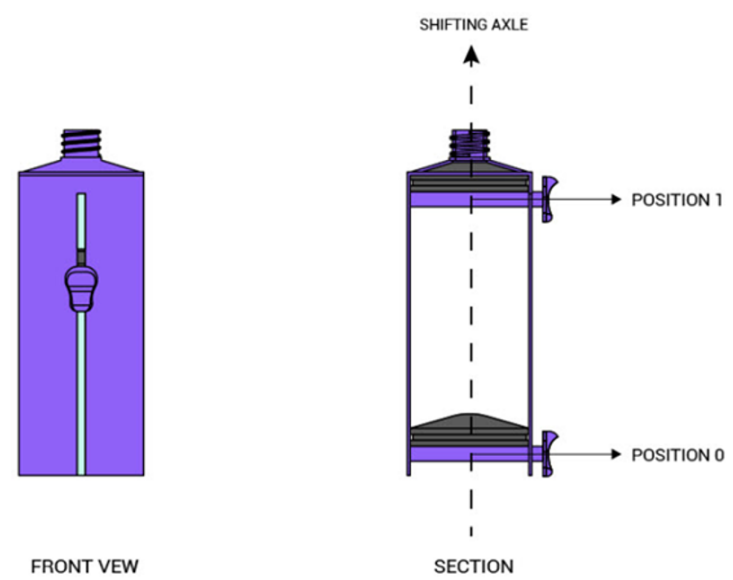

» Figure 3: Operation Mechanism of the proposed concept

In this manner, the design enables the user to exploit the entire product, by reducing the wastage, without requiring much human effort. The piston in turn, has a button extruded from the side surface, which slides between the slit, which is formed at the side of the container. At the same time, the sliding button could function as an indication of the amount of toothpaste remaining in the container. Finally, to protect the product from contact with the ambient air, the slot could be airtight with an aluminium foil, which will tear gradually during the upward 
movement of the sliding handle. Eventually, the user should use both hands to properly handle the packaging as long as the content is below $50 \%$. Later, it is possible to use only one hand. Figure 4 depicts the manner of use of that mechanism and its interaction with the user.

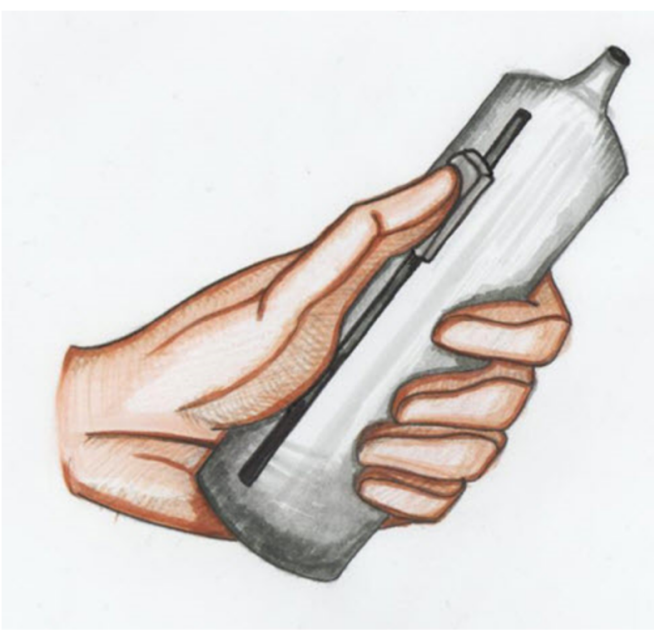

» Figure 4: Conceptual sketch of the proposed mechanism use

\section{Concept development}

The brand name chosen for the design of the first concept is "Say Cheese!", and is an alternate way, especially popular among photographers, to ask someone to smile. The objective of the specific brand is to transmit a playful experience for younger audience and this is achieved by providing a modern look, which is relevant to comic aesthetics. The message which is communicated through the design of graphic elements is the uniqueness that each individual human smile has. This uniqueness of the human denture as illustrated graphically, also serves to diversify the range of products of the same brand. This differentiation is also achieved by the use of strong and saturated colors, while further enhances the funny and relaxed mood that the brand tries to promote, while contributing to a more eye-catching result (Reimann et al., 2010; Vladić et al., 2016), in comparison with competitors, as selected colors vary considerably from those used so far in the toothpaste market.

In figure 5, the implementation of brand is presented visually on the packaging and some structural elements of the package can also be observed. The selected form is characterized by simplicity and contrasts with the loud aesthetic of the brand, in order to achieve a balance.

The name of the second brand under investigation is "Dental Fresh" and the visual communication could be considered more conventional, because design is closer to the style and aesthetics of classical toothpaste packages, as most people have in their minds, whilst the graphic references clearly refer to the content of the package. The specific aesthetic was intentionally chosen in order to place more emphasis on morphological elements of the package. The selected colors also follow the color palette of the content, and the communication of the aesthetical requirements is achieved in this manner. These are the sensation of freshness, purity, cleanliness and environmental friendliness.

Regarding the structural elements of the package, an attempt was made to further improve the ergonomic factor, compared to the previous idea so as to mainly foster their stability to hold during use. The visualization of the result is shown in figure 6 . For the outer casing transparent materials were selected in order to attract the interest of the public, and addi-

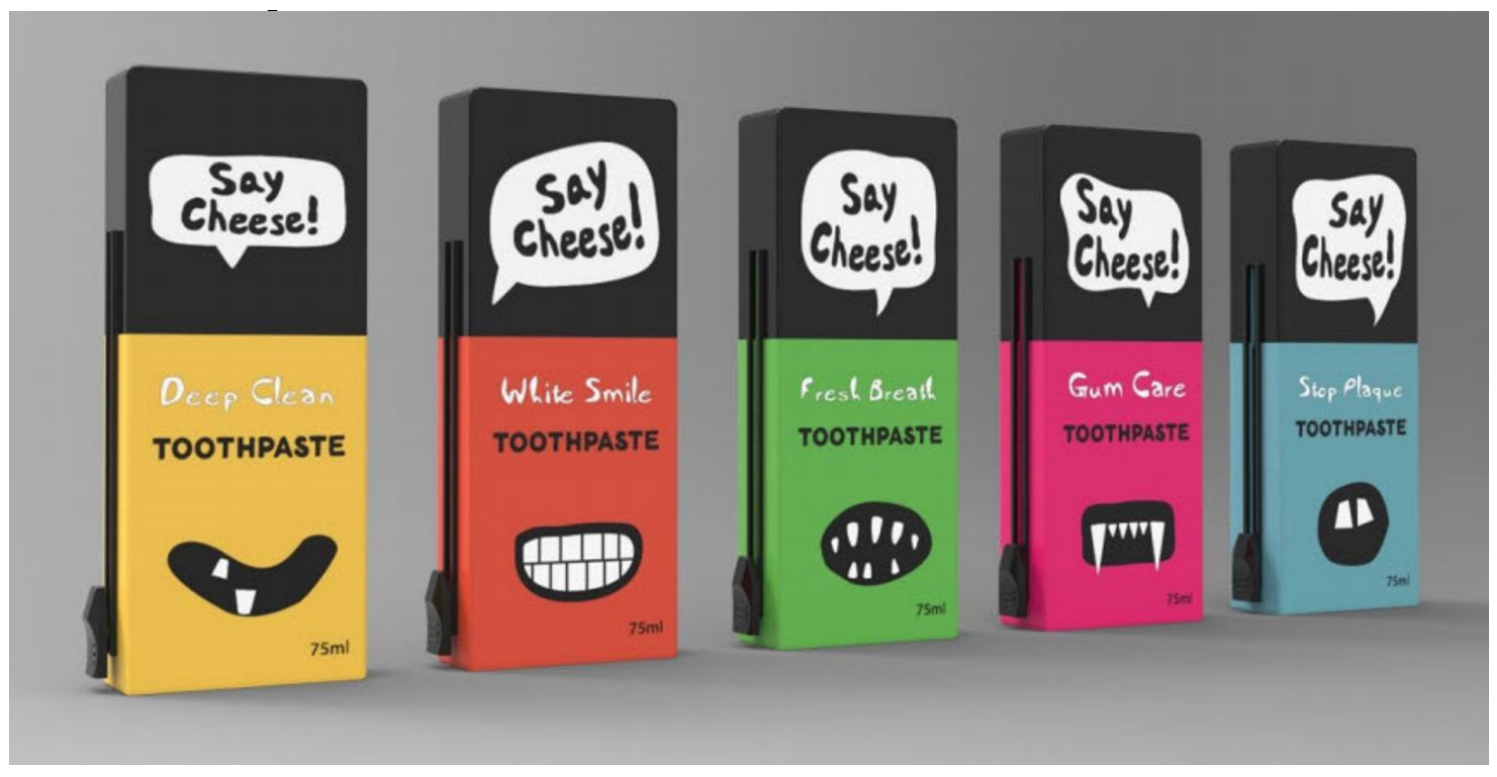

» Figure 5: Rendered image of the "Say Cheese!" concept and product range differentiation 
tionally for the label to be evident, which has been applied to the surface of the container interior part.

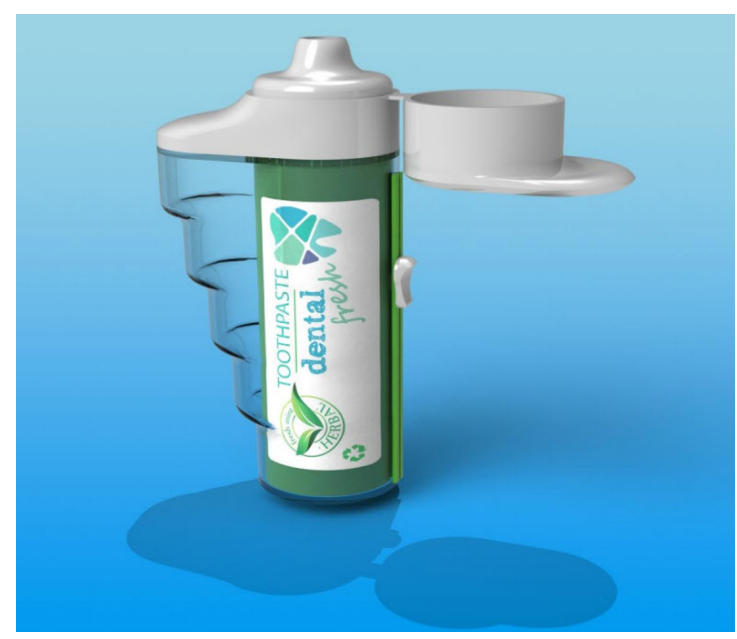

» Figure 6: Rendered image of the "Dental Fresh" concept

The name chosen for the third brand is "Sparkle" and refers symbolically to the shiny effects, which might have the use of this specific toothpaste. The brand image of this idea is further strengthened by means of graphic elements, which sought to create the sensation created by light reflection, when incident on shiny surfaces (i.e. water), through the use of geometric abstraction and different hues of the same color. Inspiration is drawn from pixel art in order to be ascribed effectively with abstract way the glowing effect.

As shown in Figure 7 product differentiation is accomplished chromatically and more vivid, RGB colors are selected, which make high contrast with the white background. Morphologically, the aerodynamic shape of the package follows the design language of the brand and the notches on the right side of the package serve as a handle for better grip during use and avoid slipperiness.

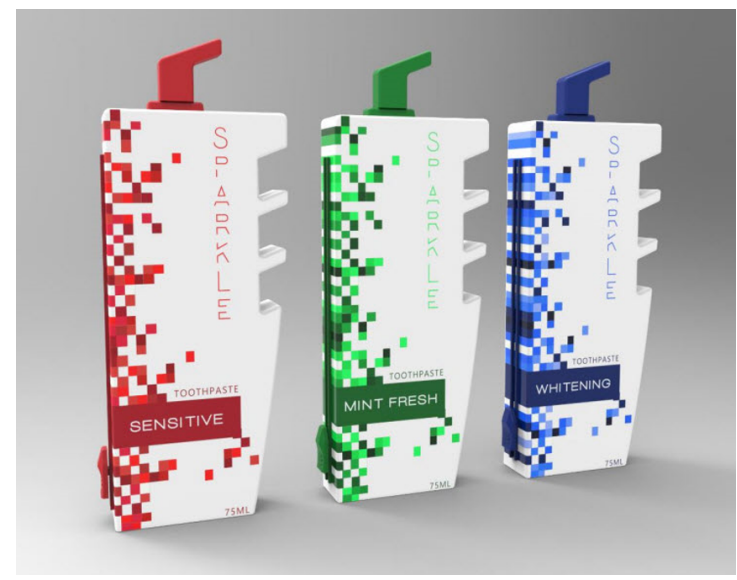

» Figure 7: Rendered image of the "Sparkle" concept and product range differentiation
The last proposed brand is named "Crystalline" and is intended to convey a sense of crystal coolness. The unusual design of the outer case, as the name implies, is inspired by the structure of crystals, while the minimalist design of the logo attempts to promote a superior quality of the product. For the design of the label, a pattern consisting of divided triangular geometric forms was created. The same applies for the formation of the logo as well. Chromatically, an attempt was made to reflect the iridescent glow of crystals with different caps used for product range differentiation.

Morphologically, as shown in Figure 8, the asymmetry of the structure of the crystals was utilized except from aesthetical reasons, for the further improvement of the ergonomic gripping of the package. During the final phase of the packaging design for "Say Cheese", "Sparkle" and "Crystalline" concepts, it is anticipated to reduce the sliding button travel by adding a simple internal "piston-spring" mechanism for aiding user with the toothpaste extraction. In addition, the slider will probably be repositioned to the middle of the shell. The mechanism (piston-spring) will be positioned just below the sliding groove since the more orthogonal-oriented shell has more room for this addition compared to the cylindrical one.

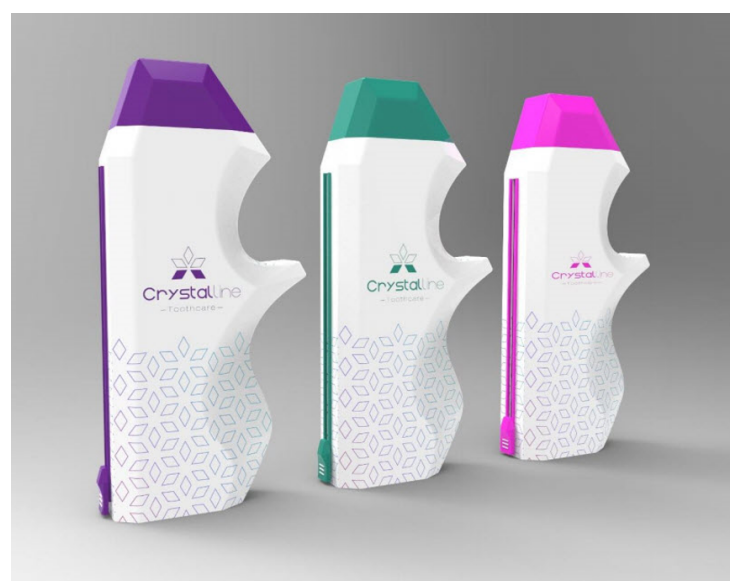

» Figure 8: Rendered image of the "Crystalline" concept and product differentiation

For the better understanding of the form of each packaging case and in order to test their operating method and ergonomic usability, physical models were created made of clay (Figure 9).

This process was particularly fruitful to study the scale and dimensions of the proposed objects, make the appropriate refinements, begin the development process and the detailed design of the concept, as well as their realistic imagery that were previously presented. 

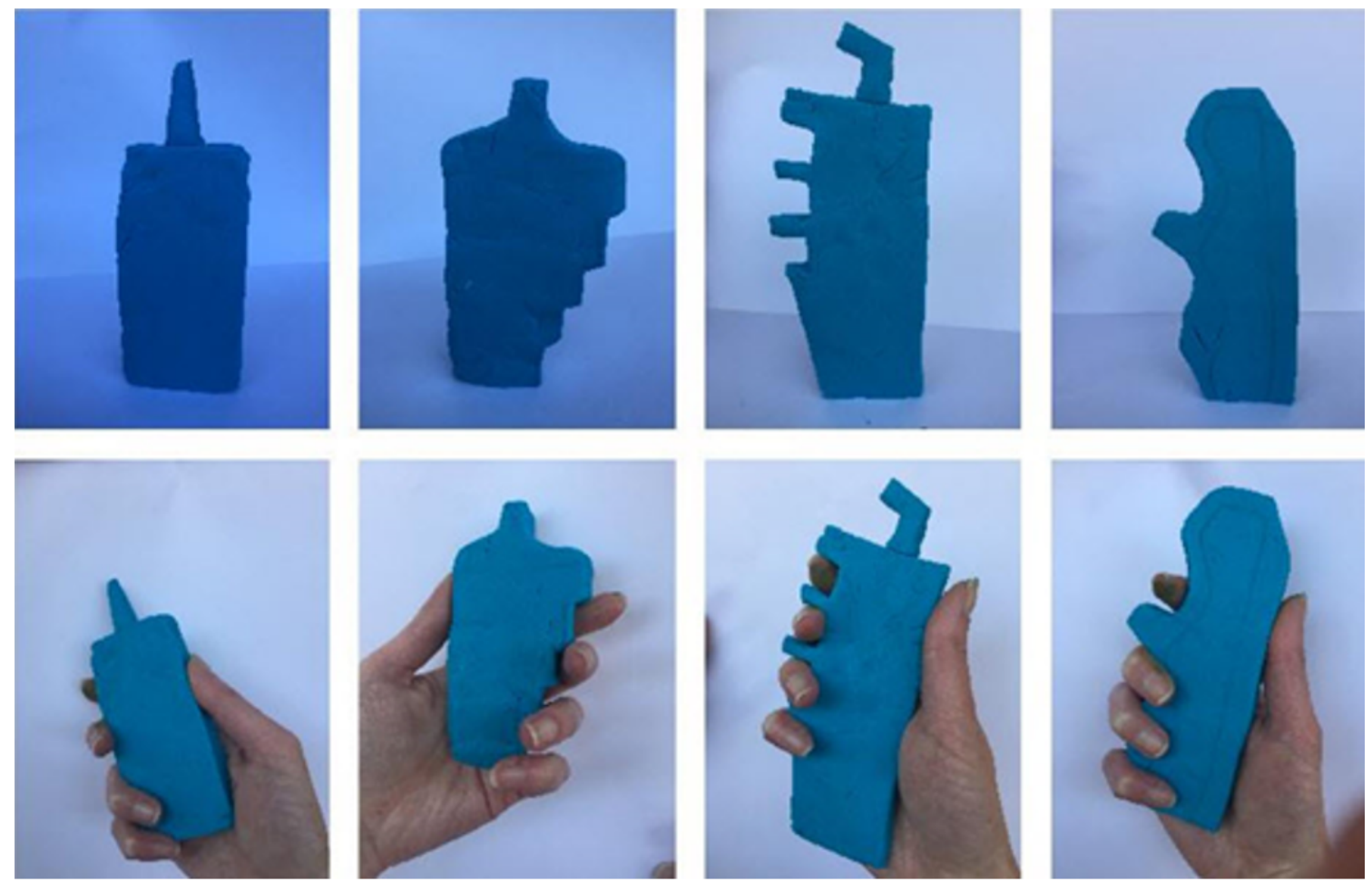

» Figure 9: Physical mockups and concept testing

\section{Detailed description of the concept parts}

Figure 10 illustrates an exploded view of the assembly and all the proposed concepts consist of four basic features. The lid, the inner vessel that contains the toothpaste, the outer casing which protects the product, and the sliding button that forces the toothpaste to extrude from the inner vessel. These parts are detachable in order to facilitate the recycling process.

In order to enable the user to exploit the entire product (by reducing the wastage without requiring much human effort), the design is based on the concept of the syringe. It consists of the main vessel, which is open at the bottom and is filled with toothpaste. The providing of the dentifrice is extracted from the vessel with the aid of a piston. The piston provides the airtight seal of the container. At the same time, a sliding button functions as remaining toothpaste indicator. To protect the product from contact with the ambient air, the slot could be airtight with an aluminum foil, which will tear gradually during the upward movement. The opening of the container has the necessary threads to screw the cap. In addition to this, the lid is either hinged or screwed cap so that during its use to be reclosable. The outer casing, has the specific structures not only for aesthetical reasons, but is designed in a way to ergonomically fit the hand of the user. Eventually, at the outer casing two thin strips of silicon are attached.
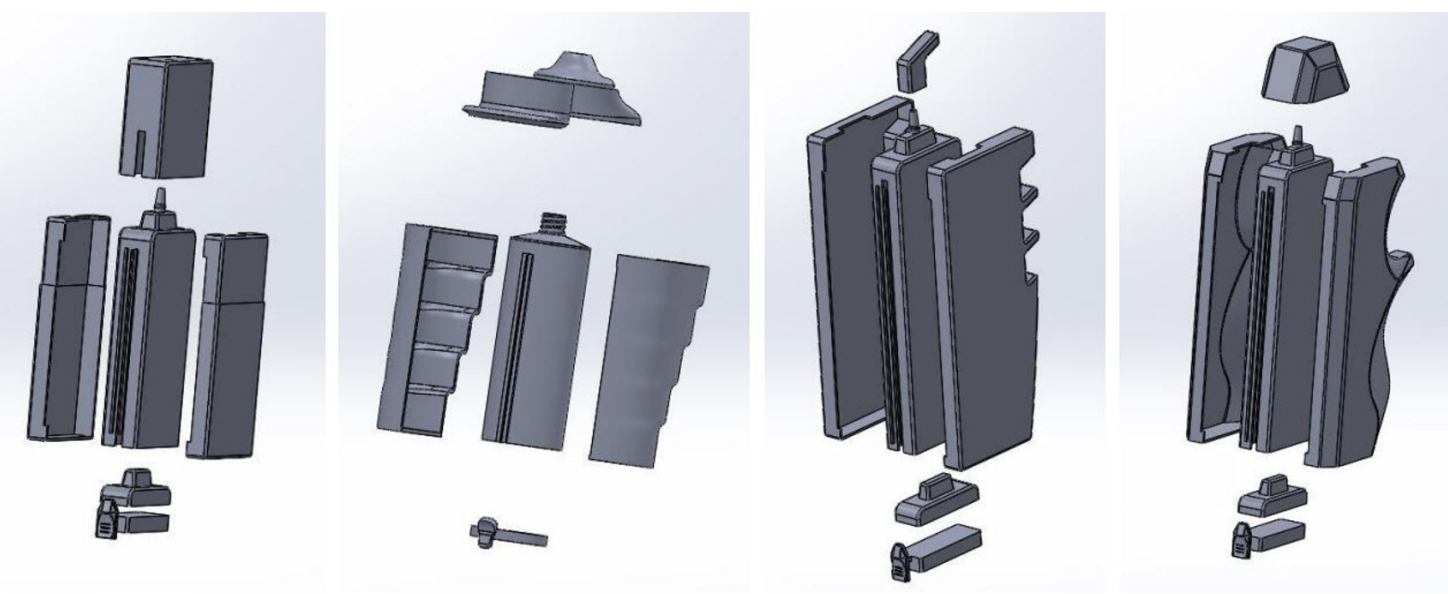

» Figure 10: Exploded views of the proposed concepts 


\section{Sustainability evaluation}

All the individual parts of the proposed concepts are designed to be from plastic materials but in order to evaluate the sustainability the fourth concept was selected due to the fact that it has the most complicated geometry. In order to select the most eco-friendly materials, a sustainability analysis has been performed in SolidWorks ${ }^{\mathrm{TM}}$ and the results are summarized in Table 2 . Additionally, the end of life management for each of the materials evaluated in this study is depicted in Figure 11.

For the design of the lid, after a brief research, there are two candidate materials, polypropylene (PP) and low density polyethylene (LDPE), which have the most appropriate mechanical properties. LDPE is flexible and tough enough, whereas PP has high stiffness, good impact balance, high gloss appearance and good hinge properties since it is fatigue resistance, making it more suitable for the hinged lid. After the life cycle assessment study of the two materials it is concluded that PP is more sustainable, although it has greater financial impact. If we compare the results found in Table 2 we can observe that PP has sufficiently improved the design. The total measurements of carbon dioxide and other greenhouse gas emissions are estimated to be $0.011 \mathrm{~kg}$. In addition, the non-renewable energy sources used during the parts lifecycle and it is estimated to $0.271 \mathrm{MJ}$. The air acidification is related with the emissions of sulfur dioxide and nitrous oxides that are responsible for the acidity of rain water, and is calculated to be $3.4 \mathrm{e}^{-5} \mathrm{~kg}$. On the other hand, water eutrophication, which concerns the overabundance of nutrients like nitrogen and phosphorous from waste water to the ecosystem, is measured to be $4.0 \mathrm{e}^{-6} \mathrm{~kg}$

For the design of the outer case, the same materials with the lid were selected, PP and LDPE, since the requirements for the mechanical properties are the same and the factor of non-breakability is very crucial in order to achieve the reusability and durability for longer lifespan. If we compare the results of the charts below, we can observe that PP has sufficiently improved the design. The total measurements of carbon-dioxide and other greenhouse gas emissions are estimated to be $0.032 \mathrm{~kg}$. Moreover, the non-renewable energy sources used during the parts lifecycle and it is estimated to $0.0824 \mathrm{MJ}$. The air acidification is related with the emissions of sulfur dioxide and nitrous oxides that are responsible for the acidity of rain water, and is calculated to be $1.0 \mathrm{e}^{-4} \mathrm{~kg}$. On the other hand, water eutrophication which concerns the overabundance of nutrients like nitrogen and phosphorous from waste water to the ecosystem, is measured to be $1.2 \mathrm{e}^{-5} \mathrm{~kg}$.

For the inner vessel, the initial material for the test was PVC. After several tests with materials that have similar properties, we can conclude that high density polyethylene (HDPE), has improved the environmental impact of the design. It is worth mentioning that the total energy consumption for the both materials is approximately the same, since the energy required for the material procurement is slightly worse.

The plunger with the sliding button, requires a material that is rigid enough in order not to break easily due to the forces that are being applied to the slider. The baseline material was set to HDPE, whereas PP slightly improved the environmental impact.

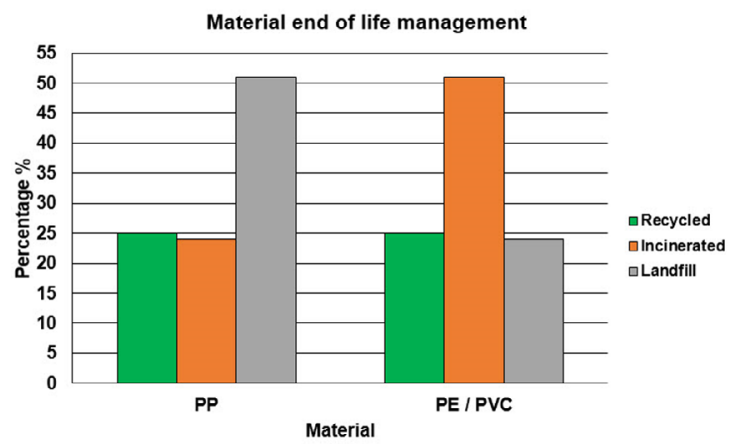

» Figure 11: Chart for the end of life management of proposed each material

\section{Table 2}

Sustainability report results

\begin{tabular}{|c|c|c|c|c|c|}
\hline Part & Material & $\begin{array}{l}\text { Carbon footprint } \\
\left(\mathrm{kg} \text { of } \mathrm{CO}_{2}\right)\end{array}$ & $\begin{array}{l}\text { Total energy } \\
\text { consumption } \\
\text { (MJ) }\end{array}$ & $\begin{array}{l}\text { Air acidification } \\
\left(\mathrm{kg} \text { of } \mathrm{SO}_{2}\right)\end{array}$ & $\begin{array}{c}\text { Water } \\
\text { eutrophication } \\
\left(\mathrm{kg} \text { of } \mathrm{PO}_{4}\right)\end{array}$ \\
\hline Lid & $\begin{array}{l}\text { PP } \\
\text { LDPE }\end{array}$ & $\begin{array}{l}0.011 \\
0.014\end{array}$ & $\begin{array}{l}0.271 \\
0.289\end{array}$ & $\begin{array}{l}3.4 e^{-5} \\
3.6 e^{-5}\end{array}$ & $\begin{array}{l}4.0 e^{-6} \\
5.8 e^{-6}\end{array}$ \\
\hline Outer case & $\begin{array}{l}\text { PP } \\
\text { LDPE }\end{array}$ & $\begin{array}{l}0.032 \\
0.041\end{array}$ & $\begin{array}{l}0.824 \\
0.828\end{array}$ & $\begin{array}{l}1.0 e^{-4} \\
1.1 e^{-4}\end{array}$ & $\begin{array}{l}1.2 \mathrm{e}^{-5} \\
1.8 \mathrm{e}^{-5}\end{array}$ \\
\hline Inner vessel & $\begin{array}{l}\text { HDPE } \\
\text { PVC }\end{array}$ & $\begin{array}{l}0.046 \\
0.069\end{array}$ & $\begin{array}{l}1.2 \\
1.2\end{array}$ & $\begin{array}{l}1.5 e^{-4} \\
2.3 e^{-4}\end{array}$ & $\begin{array}{l}1.7 e^{-5} \\
3.6 e^{-5}\end{array}$ \\
\hline $\begin{array}{l}\text { Plunger with } \\
\text { slider button }\end{array}$ & $\begin{array}{c}\text { PP } \\
\text { HDPE }\end{array}$ & $\begin{array}{l}0.010 \\
0.013\end{array}$ & $\begin{array}{l}0.273 \\
0.281\end{array}$ & $\begin{array}{l}3.4 \mathrm{e}^{-5} \\
3.6 \mathrm{e}^{-5}\end{array}$ & $\begin{array}{l}4.0 e^{-6} \\
5.9 e^{-6}\end{array}$ \\
\hline
\end{tabular}




\section{Conclusions}

Despite the fact that toothpaste market is one of the most dynamic segments of the oral care market, little innovation has been occurred on the packaging of toothpaste, considering the fact that the market is still dominated by the tube, a packaging device that was initially launched in 1892. Since traditional toothpaste tubes cause many functional and environmental problems, in the specific project has been made an effort to propose a new packaging design that is not only environmental friendly, since all the parts are detachable and from recyclable materials, that facilitate the process of separation and recycling and allows full export of the product from the package, but is also user-friendly. To enhance the environmental awareness, the device could also be reusable and the inside vessel containing the toothpaste, could be purchased separately in the market, as a replacement part. As far as the methodology of design process is concerned, it is concluded that every project has needs, that are unique and factors such as the objective of the project, the available information, the provided accessibility and timing constraints, which may affect the order and flow of the designing phases, while the need for evaluation, with the ultimate aim to filter information deemed necessary at each step, like the continuous feedback with the requirements.

The design proposals derived from this process, seems to achieve the objectives set on the design brief. However it is worth noting that the simultaneous satisfaction of all requirements is usually not feasible and constitutes a major challenge in the design process. For the selection of the material, it is concluded that is a huge chapter in product design application, and despite the fact that there are materials that are more sustainable than others, more considerations should be taken into account, in terms of financial impact, mechanical properties, optical properties, in order the design to give the best feeling to the product and find a better balance. At the same time, further research could be done with materials which allow full slipperiness of viscous liquids, in order to solve the problem of residues. Nevertheless, for the needs of this study, the used materials were more than one. PP was chosen as the best suit for the lid, the outer case and the plunger, whereas HDPE was chosen for the inner vessel.

Furthermore, the observation that more and more people have become conscientious about the environment and the products that chooses to use is very encouraging. The social responsibility that the designer has must be stressed and often the need for innovation and originality, in terms of improving the comfort of everyday life, can lead to waste of materials and destructive solutions for environment. The simplicity of the past might be an innovation of the future, since less is more.

\section{References}

Alexopoulos, V., Kyratsis, P. \& Efkolidis, N. (2011) Feta Cheese Packaging Designs using Advanced CAD/CAM Systems. The Cyprus Journal of Sciences. 9, 49-57.

Carli Lorenzini, G. \& Olsson, A. (2019) Towards patient-centered packaging design: An industry perspective on processes, functions, and constraints. Packaging Technology and Science. 32 (2), 59-73. Available from: doi:10.1002/pts.2419

Dimou, E., Manavis, A., Papachristou, E. \& Kyratsis, P. (2017) A Conceptual Design of Intelligent Shoes for Pregnant Women. In: Rinaldi, R. and Bandinelli, R. (eds.) Proceedings of IT4Fashion 2016: Business Models and ICT Technologies for the Fashion Supply Chain. Pp. 69-77. Available from: doi: 10.1007/978-3-319-48511-9_6

Efkolidis, N. \& Kyratsis, P. (2012) Ecology Push : A Novel Methodology in Product Design. International Journal of Modern Engineering Research. 2 (2), 89-94.

Elliot, D. (2010) Markets: Toothpaste seeks fresh ideas, PackagingNews. Packaging News. Available from: https://www.packagingnews. co.uk/news/markets-toothpaste-seeks-freshideas-05-05-2010 [Accessed: 19th May 2020]

INCPEN (2011) Why products are packaged the way they are. Industry Council for Packaging \& the Environment. Available from: http:// www.incpen.org/docs/WPAPTWTAJune $\% 20$ 2011.pdf [Accessed: 19th May 2020]

Kovačević, D., Brozović, M. \& Itrić Ivanda, K. (2019) Eco-mark on product packaging and its effect on the perception of quality. Journal of Graphic Engineering and Design. 10 (2), 17-24. Available from: doi: 10.24867/JGED-2019-2-017

Kyratsis, P., Dimou, E., Manavis, A. \& Bilalis, N. (2015) An Inspired from Nature Design Methodology for the Fashion Industry. Advanced Technologies in Designing and Progressive Development of Manufacturing Systems. 760, 33-38. Available from: doi: 10.4028/www.scientific.net/AMM.760.33

Manavis, A., Sourris, T., Dimou, E., Efkolidis, N. \& Kyratsis, P. (2019) An Inspiration from Nature Design Methodology for In-Store Displays. Journal of Packaging Technology and Research. 3 (2), 141-148. Available from: doi: 10.1007/s41783-019-00057-w

Reimann, M., Zaichkowsky, J., Neuhaus, C., Benderd, T. \& Weber, B. (2010) Aesthetic package design: A behavioral, neural, and psychological investigation. Journal of Consumer Psychology. 20 (4), 431-441. Available from: doi: 10.1016/j.jcps.2010.06.009

Sriram, S. \& Pugalanthi, S (2013) A Study on the Purchasing Behaviour of Consumers towards Toothpaste with Special Reference to Madurai District. Indian Journal of Research. 2 (7), 184-187.

Slater, S. \& Chrichton, T. (2011) Recycling of Laminated Packaging: Trials to Optimise Pilot Plant for Recycling of Laminated Packaging Wastes. Oxon, 
WRAP. Available from: http://www.wrap.org.uk/ sites/files/wrap/Recycling\%20 of\%20laminated\%20 packaging.pdf [Accessed: 19th May 2020]

Stypka, T., Stypka, A., Hultman, B., Mikosz, J., Plaza, E. \& Cimochowicz - Rybicka, M. (2005) Municipal solid waste and sludge handling - sustainability and trends. Stockholm, Royal Institute of Technology (KTH).

Svanes, E., Vold, M., Møller, H., Pettersen, M. K., Larsen, H. \& Hanssen, O. J. (2010) Sustainable packaging design: a holistic methodology for packaging design. Packaging Technology and Science. 23 (3), 161-175. Available from: doi: 10.1002/pts.887

Ulrich, K. T. \& Eppinger, S. T. (2012) Product Design and Development - 5th edition. New York, McGraw-Hill.

Vasileiadis, T., Tzotzis, A., Tzetzis, D. \& Kyratsis, P. (2019) Combining product and packaging design for increased added value and customer satisfaction. Journal of Graphic Engineering and Design. 10 (2), 5-15. Available from: doi: 10.24867/JGED-2019-2-005

Vladić, G., Kecman, M., Kašiković, N., Pál, M. \& Stančić, M. (2016) Influence of the shape on the consumers perception of the packaging attributes. Journal of Graphic Engineering and Design. 6 (2), 27-32.

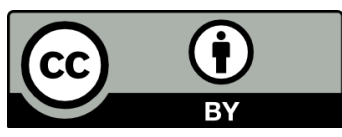

(C) 2020 Authors. Published by the University of Novi Sad, Faculty of Technical Sciences, Department of Graphic Engineering and Design. This article is an open access article distributed under the terms and conditions of the Creative Commons Attribution license 3.0 Serbia (http://creativecommons.org/licenses/by/3.0/rs/). 